\title{
Environmental and occupational respiratory diseases - 1063. Spirometric abnormalities in non smoking bus drivers of hyderabad
}

\author{
Mohammed Faisal", Prasad Eswara Chelluri, Saikrishna Singaraju, Jayasri Helen Gali, Sayeed Ahmed, P Srinivas
}

From 2nd WAO International Scientific Conference (WISC 2012)

Hyderabad, India. 6-9 December 2012

Aim
The prevalence of COPD in non-smoking bus drivers of
Hyderabad city (A.P State Road Transport Corporation).

\section{Background}

Hyderabad metro has high atmospheric pollution with a mean TSPM $280 \mathrm{mg} /$ cubic meter of air, sometimes as high as 400 .

Vehicles contribute $50 \%$ of the total air pollution in urban areas [1].

\section{Subjects}

82 Non-smoking male bus drivers of APSRTC. Buses are non-air-conditioned with open windows.

\section{Methods}

An occupational-demographic data was obtained and American Thoracic Society - Division of Lung Disease (ATS) Questionnaire administered. Subjects were enrolled between May and September 2012. Spirometry performed using an auto calibrated system (Microlab, Kent, UK) and abnormalities were classified and graded (GOLD Guidelines 2005). The data were statistically treated for correlation between symptoms, spirometric abnormalities and work experience.

\section{Results}

Age $38 \pm 8.75 \mathrm{yrs}$; BMI $23.9 \pm 2.8$

COPD was diagnosed in 35 out of $82(42.6 \%)$ based on spirometry. COPD was "mild" in 16 (45\%), "moderate" in $18(51.4 \%)$ and "severe" in $1(2.8 \%) .13$ of 30 subjects with work experience of $>10$ years had COPD.
22 of 52 subjects with work experience of $<10$ years had COPD (Fishers exact test $(\mathrm{p}<0.01)$.

The spirometric indices demonstrated difference between Group A i.e. drivers with $>10$ years experience and Group B $<10$ years. FEV 1 was lower in Group A vs. Group B (2.49 \pm 0.65 Vs $2.73 \pm 0.49 ; \mathrm{p}=0.06)$. PEFR (5.42 \pm 2.11 Vs 6.48 $\pm 1.91 ; \mathrm{p}=0.02$ ), FEV6, FEV1/FEV6, FEF2575, post bronchodilator reversibility were lower in Group A vs. Group B though statistically not significant.

Symptom profile: shortness of breath in 35 (cough in $12(14.6 \%)$, morning sputum in $15(18 \%)$, wheeze in 6 , recurrent sinusitis in 7 (8\%).

\section{Conclusion}

The present sample study of non smoking bus drivers in an urban area of India using ATS questionnaire and spirometry is, perhaps, the first to the best of our knowledge. About $40 \%$ of the subjects had COPD. Environmental preventive measures required.

Published: 23 April 2013

\section{Reference}

1. [http://searchandhra.com/articles/pollution-on-the-rise-in-hyderabad].

doi:10.1186/1939-4551-6-S1-P61

Cite this article as: Faisal et al.: Environmental and occupational respiratory diseases -1063 . Spirometric abnormalities in non smoking bus drivers of hyderabad. World Allergy Organization Journal 2013 6(Suppl 1):P61. 